\title{
Cross-cultural adaptation of the Maltreatment and Abuse Chronology of Exposure (MACE) scale to Brazilian Portuguese
}

\author{
Adaptação transcultural da escala Maltreatment and Abuse Chronology of \\ Exposure (MACE) para o português brasileiro
}

Bruno Kluwe-Schiavon, ${ }^{1,2}$ Thiago Wendt Viola, ${ }^{3}$ Rodrigo Grassi-Oliveira ${ }^{1,3}$

\begin{abstract}
Introduction: There is strong evidence to indicate that childhood maltreatment can negatively affect both physical and mental health and there is increasing interest in understanding the occurrence and consequences of such experiences. While several tools have been developed to retrospectively investigate childhood maltreatment experiences, most of them do not investigate the experience of witnessing family violence during childhood or bullying exposure. Moreover, the majority of scales do not identify when these experiences may have occurred, who was involved or the feelings evoked, such as helplessness or terror. The Maltreatment and Abuse Chronology of Exposure (MACE) scale was developed to overcome these limitations.

Objective: In view of the improvements over previous self-report instruments that this new tool offers and of the small number of self-report questionnaires for childhood maltreatment assessment available in Brazil, this study was conducted to conduct cross-cultural adaptation of the MACE scale for Brazilian Portuguese.

Method: The following steps were performed: translation, back-translation, committee review for semantic and conceptual evaluation, and acceptability trial for equivalence.

Results: Semantic and structural changes were made to the interview to adapt it for the Brazilian culture and all 75 of the items that comprise the longer version of MACE were translated. The results of the acceptability trial suggest that the items are comprehensible. Conclusion: The MACE scales may be useful tools for investigation of childhood maltreatment and make a valuable contribution to research in Brazil. Future studies should consider testing the availability and reliability of the three versions of the instrument translated into Brazilian Portuguese.
\end{abstract}

Keywords: Early life stress, neglect, abuse, validation, instrument.

\section{Resumo}

Introdução: Há evidências robustas na literatura indicando que os maus-tratos na infância podem afetar negativamente a saúde física e mental. Além disso, há um crescente interesse em compreender a ocorrência e as consequências dessas experiências. Vários instrumentos vêm sendo desenvolvidos para investigar retrospectivamente experiências de maus-tratos na infância, mas a maioria deles não investiga a experiência de testemunhar violência familiar durante a infância ou a ocorrência de bullying. Além disso, a maioria não identifica quando as experiências ocorreram, quem estava envolvido ou os sentimentos que evocaram, como desespero ou terror. A escala Maltreatment and Abuse Chronology of Exposure (MACE) foi desenvolvida para superar essas limitações.

Objetivos: Considerando as vantagens dessa nova escala em relação aos instrumentos de autorrelato existentes e o reduzido número de questionários de autorrelato disponíveis no Brasil para avaliar maus-tratos na infância, este estudo teve como objetivo conduzir a adaptação transcultural da escala MACE para o português brasileiro. Método: Foram realizadas as etapas de tradução, retrotradução, análise de equivalência semântica e correspondência conceitual por um comitê avaliador e teste de aceitabilidade.

Resultados: Adaptações semânticas e estruturais foram realizadas na entrevista para a realidade cultural brasileira, e todos os 75 itens incluídos na versão estendida da MACE foram traduzidos. Os resultados do teste de aceitabilidade sugerem que os itens foram adequadamente compreendidos.

Conclusões: A escala MACE é uma ferramenta útil para a investigação de maus-tratos na infância, contribuindo para a pesquisa no Brasil. Futuros estudos devem considerar testar a validade e fidedignidade das três versões do instrumento traduzidas para o português do Brasil.

Descritores: Estrese precoce, negligência, abuso, validação, instrumento.

\footnotetext{
${ }^{1}$ Developmental Cognitive Neuroscience Lab (DCNL), Programa de Pós-Graduação em Psicologia, Pontifícia Universidade Católica do Rio Grande do Sul (PUCRS), Porto Alegre, RS, Brazil. ${ }^{2}$ Experimentelle und Klinische Pharmakopsychologie, Psychiatrische Universitätsklinik Zürich, Zürich, Switzerland. ${ }^{3}$ Programa de PósGraduação em Pediatria e Saúde da Criança, PUCRS, Porto Alegre, RS, Brazil.

Financial support: none.

Submitted Aug 26 2015, accepted for publication Oct 17 2015. No conflicts of interest declared concerning the publication of this article.

Suggested citation: Kluwe-Schiavon B, Viola TW, Grassi-Oliveira R. Cross-cultural adaptation of the Maltreatment and Abuse Chronology of Exposure (MACE) scale to Brazilian Portuguese. Trends Psychiatry Psychother. 2016;38(1):33-39. http://dx.doi.org/10.1590/2237-6089-2015-0051
} 


\section{Introduction}

Reports of abandonment, abuse, infanticide, and other forms of violence against children have been documented for a long time, dating back to ancient cultures. ${ }^{1}$ However, understanding of the importance of preventing these experiences has increased over recent decades in response to strong evidence that childhood maltreatment can negatively affect both physical and mental health.2,3 Notwithstanding, much better understanding of the occurrence and consequences of this problem is still required if it is to be solved and prevented. 4

These and other prospects have motivated development of refinements in the study of the epidemiology of childhood abuse and neglect. Several tools have been developed to retrospectively investigate childhood maltreatment experiences with adolescents and adults with satisfactory reliability and validity. ${ }^{5}$ The self-report instruments most widely used in recent years are the Childhood Trauma Questionnaire (CTQ), ${ }^{6,7}$ the Childhood Experience of Care and Abuse Interview (CECA), ${ }^{8}$ the Adverse Childhood Experience (ACE) instrument ${ }^{9}$ and the Childhood Experience of Care and Abuse Questionnaire (CECA-Q). ${ }^{10}$ While they each have their peculiarities and differences, these questionnaires converge on exploring three kinds of abuse-related traumatic event (physical, emotional and sexual abuse) and two types of neglect experience (physical and emotional neglect). ${ }^{5}$ These instruments have therefore been making considerable contributions to the fields of clinical practice and research into childhood maltreatment and have been adapted for and translated into different languages. For instance, we successfully adapted the CTQ for Brazilian Portuguese and then investigated its psychometric properties. ${ }^{11}$

Nevertheless, these instruments have important limitations. According to Teicher \& Parigger, the experience of witnessing family violence during childhood is barely investigated by the CTQ, ACE or CECA-Q, even though this kind of maltreatment can increase the risk of mental disorders. ${ }^{12}$ Peer victimization, such as exposure to bullying, is also neglected by current instruments and the CTQ, CECA-Q and ACE do not assess such experiences. Additionally, these retrospective instruments fail to obtain data on when during development maltreatment experiences occurred, but this information appears to be extremely important when it is considered that there are windows of vulnerability in the risk of psychiatric disorders.

To overcome these limitations, Teicher \& Parigger developed the Maltreatment and Abuse Chronology of Exposure (MACE) battery to investigate a broader range of childhood maltreatment experiences and to obtain information about when such experiences occur. The items that make up the MACE were chosen on the basis of a review of best-fitted questions from different childhood maltreatment assessment tools ( $A C E, C T Q$ and others). The resulting questionnaire comprises 52 questions and for each item there are check boxes for indicating at what age exposure occurred (1-18 years). Additionally, according to analysis of latent constructs, the MACE items assess ten types of childhood abuse and neglect experiences, as follows: emotional neglect, parental nonverbal emotional abuse, parental physical maltreatment, parental verbal abuse, peer emotional abuse, peer physical bullying, physical neglect, sexual abuse, witnessing interparental violence and witnessing violence to siblings.

\section{MACE, Maltreatment and Abuse Exposure Scale (MAES) and MACE-X}

The MACE scale is a 52 -item scale that assesses the degree of exposure to ten types of abuse, as follows: emotional neglect (items 38, 39, 42, 43, 52), non-verbal emotional abuse (items 5, 40, 41, 48, 49, 50), parental physical maltreatment (items $6,7,8,9,10,11$ ), parental verbal abuse (items $1,2,3,4$ ), peer emotional abuse (items 26, 27, 28, 29, 30), peer physical bullying (items $31,32,33,34,35$ ), physical neglect (items 44, 45, 46, 47,51 ), sexual abuse (items 12, 13, 14, 19, 20, 36, 37), witnessing interparental violence (items 21, 22, 23, 24, 25) and witnessing violence to siblings (items 15, 16, $17,18)$. Additionally, MACE provides check boxes for the respondent to indicate ages at which exposure to these experiences occurred (from 1 to 18 years).

There is also another version, called MAES, which has the same 52 items as MACE, but only investigates the degree of exposure to the 10 types of abuse, without the additional check boxes.

Finally, there is a third version, called MACE-X, which is the first version of the original tool and has 75 items with check boxes to indicate age of exposure. The MACE-X version is available to researchers who intend to develop their own versions of the instrument, selecting items that better illustrate different levels and specific early life stress exposures. Moreover, MACE-X also allows respondent to indicate whether some of the stressful events led to feelings of helplessness or terror.

The original MACE exhibited very reliable psychometric properties. For instance, correlation scores ranged from good to excellent in the instrument's test-retest reliability for overall degree of exposure to distinct types 
of maltreatment. Moreover, concerning the association between early life stress and mental disorders, the MACE scores were found to better predict psychiatric outcomes compared with the CTQ and the ACE. ${ }^{12}$ Hence, in view of the improvements over previous self-report instruments offered by this new tool and of the low number of selfreport questionnaires for assessment of childhood maltreatment available in Brazil, the aim of this study was to perform a cross-cultural adaptation of all three versions of the MACE scale (MACE, MACE-X and MAES) into Brazilian Portuguese.

\section{Method}

\section{Adaptation procedures}

The study was conducted according to the International Test Commission procedures for test development, translation and cross-cultural adaptation. ${ }^{13}$ Therefore, the following steps were performed: 1) translation, 2) back- translation, 3) committee review for semantic and conceptual evaluation, and 4) acceptability trial for equivalence. ${ }^{13,14}$ See Figure 1 for an illustration of all procedures.

\section{Translation}

The translation procedure was performed by a bilingual psychologist with experience in interviewing traumatized patients and good knowledge of trauma and stress terminology, after obtaining permission in writing from the original author (M. H. Teicher). This translator was instructed to emphasize the conceptual elements rather than translate literally and the need to use natural and acceptable language was stressed. Additionally, the translator was instructed to be concise in formulating questions, avoiding using professional terms that might not be understood in everyday life and making sure that all questions would be applicable to both male and female respondents. The result of this process was a complete translated version of the questionnaire (translated version).

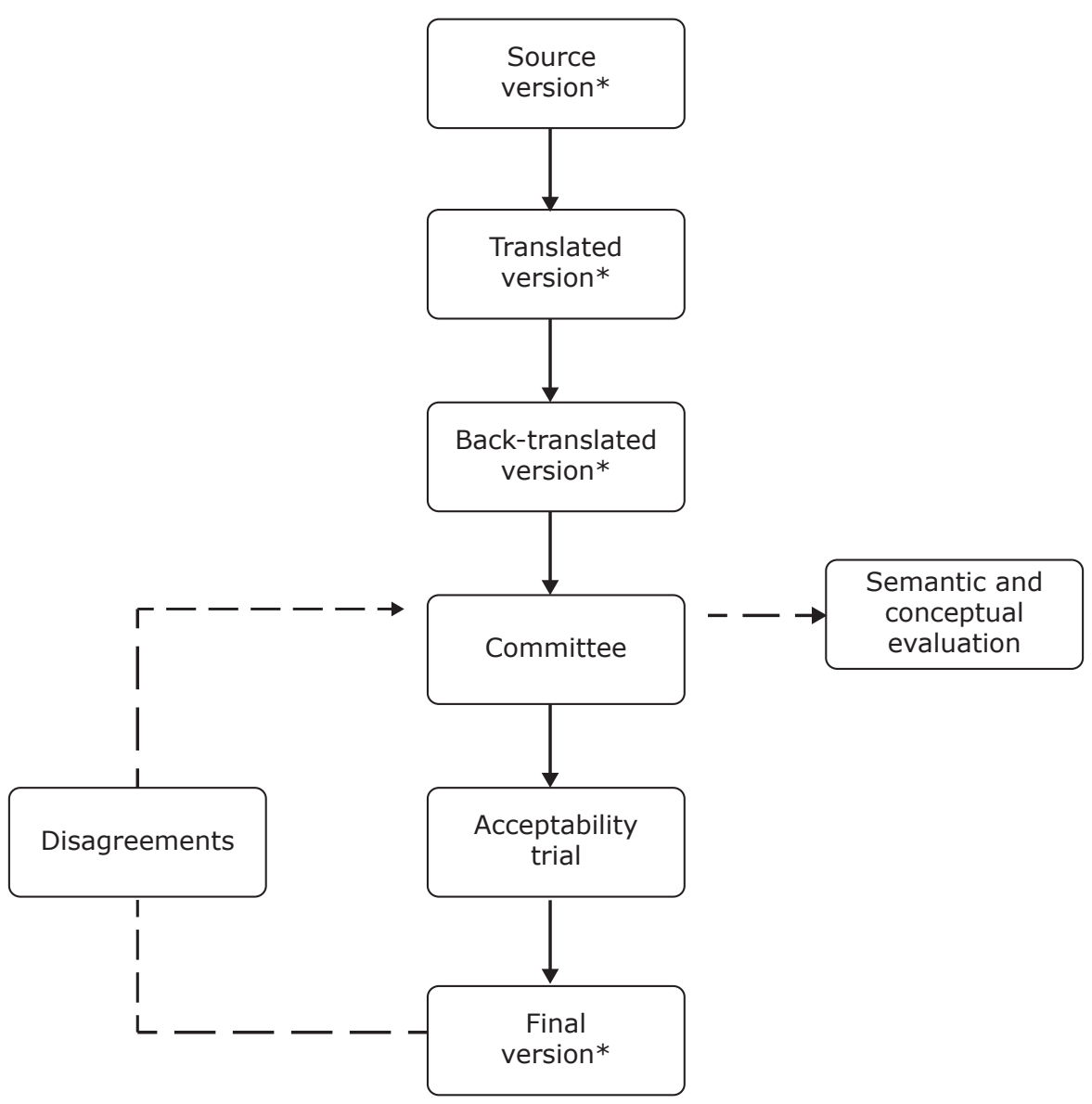

Figure 1 - Flowchart of adaptation procedures. * Information shown in Table 1. 


\section{Back-translation}

A qualified professional translation services company was hired to conduct a back-translation, in order to identify possible misunderstandings in the first translation, such as ambiguities and failures to adapt to the target cultural context. The professionals were not aware of the intent or concepts underlying the material, in order to avoid being influenced by the translation, as recommended by guidelines. ${ }^{13,15}$ As in the initial translation, the emphasis in the back-translation was also on conceptual and cultural equivalence, rather than on literal linguistic equivalence. The result of this process was a second version of the questionnaire (back-translated version).

\section{Semantic and conceptual evaluation}

After the back-translation procedure, a bilingual committee was instructed to perform semantic and conceptual evaluation of the entire modified material. The committee was made up of two psychologists with good knowledge of trauma and stress terminology and with experience in interviewing traumatized patients and performing translation of psychological instruments to Brazilian Portuguese (BKS, TWV). Additionally, a senior researcher (RGO) with vast clinical and research experience in trauma and early life stress joined the bilingual committee. The committee was instructed to attest to the general meaning of terms and ensure that the translation was fully comprehensible for cross-cultural equivalence.

\section{Acceptability trial}

An acceptability trial was performed using a probe technique in order to test whether the scale was comprehensible to the target population. ${ }^{15}$ This step was conducted as follows: five undergraduate students were asked to judge their understanding of each item, rating them from 0 (no understanding) to 5 (complete understanding) on a verbal numeric scale. If these evaluators reported values lower than 4 or had any difficulties or doubts during the task, they provided written suggestions and their feedback would be returned to the committee for a second review. Once the acceptability trial was complete and all corrections made, the final version was concluded.

\section{Results}

The entire material adapted comprises 75 items and Table 1 summarizes all of the preplanned steps that were completed and the most important conceptual and semantic alterations that proved necessary during the translation and adaptation procedures. The full version scales (MACE, MACE-X, and MASE) are available as supplementary material online.

With regard to semantic equivalence, some sentences underwent structural modification to achieve similarity to the original meaning. For example, item 15 was initially translated as "Fizeram você tocá-los de um jeito sexual," but considering usage in colloquial language, it was adapted to "Você tocou o corpo de alguém de uma forma sexual." A significant structural change was made in item 11 as well. Here the committee adapted the sentence "Spanked you on your bare (unclothed) buttocks," to "Retiraram suas calças e bateram em suas nádegas," which could be literally back-translated as "Took off your pants and spanked your buttocks." This decision was taken because the committee decided that the first translated version "Espancaram suas nádegas nuas (sem roupa)" was not normal in Brazilian Portuguese. Moreover, in addition to changes to sentence structure, the term "um jeito" was adapted to "uma maneira." Similar semantic adaptations were performed for items 4, 14 and 23 of the MACE-X, as shown in Table 1 . Another semantic adaptation was made for item 42, relating to use of the prepositions "or" and "from." Finally, a semantic adaptation was made between the back-translated version and the final version related to the subjects of sentences. In the source version the subjects were often omitted (understood by assumption) and so the same sentence structure was maintained in the final version, removing the subject "they" from the beginnings of sentences in the back-translated version.

The conceptual correspondence step also detected a need for some adaptations. The term "derogatory" in item 31 had initially been translated as "ofensivas", which was back-translated as "hurtful." However, the committee considered that the term "ofensivas" (offensive) denoted insult, whereas the term "humilhantes" (humiliating) would be more appropriate for expressing a low opinion of someone or something, and is a more common usage in the Brazilian population than "depreciativas" (derogatory). Similarly, the term "spanked" was translated as "espancaram" and back-translated as "beat." The committee then adapted the Portuguese version to "bateram." A significant conceptual alteration was made in items 46 and 50, which use the term "date," for which there is no equivalent word or term in Brazilian Portuguese. Because of this, the committee decided to use the term "pessoa próxima a você" and described examples, denoting a romantic relationship, such as girlfriend, boyfriend, romantic or intimate partner. Another conceptual adaptation was made to the term "sexual intercourse," which had been literally translated as "intercurso sexual," but was adapted by the committee to "relações sexuais" in order to facilitate comprehension. 


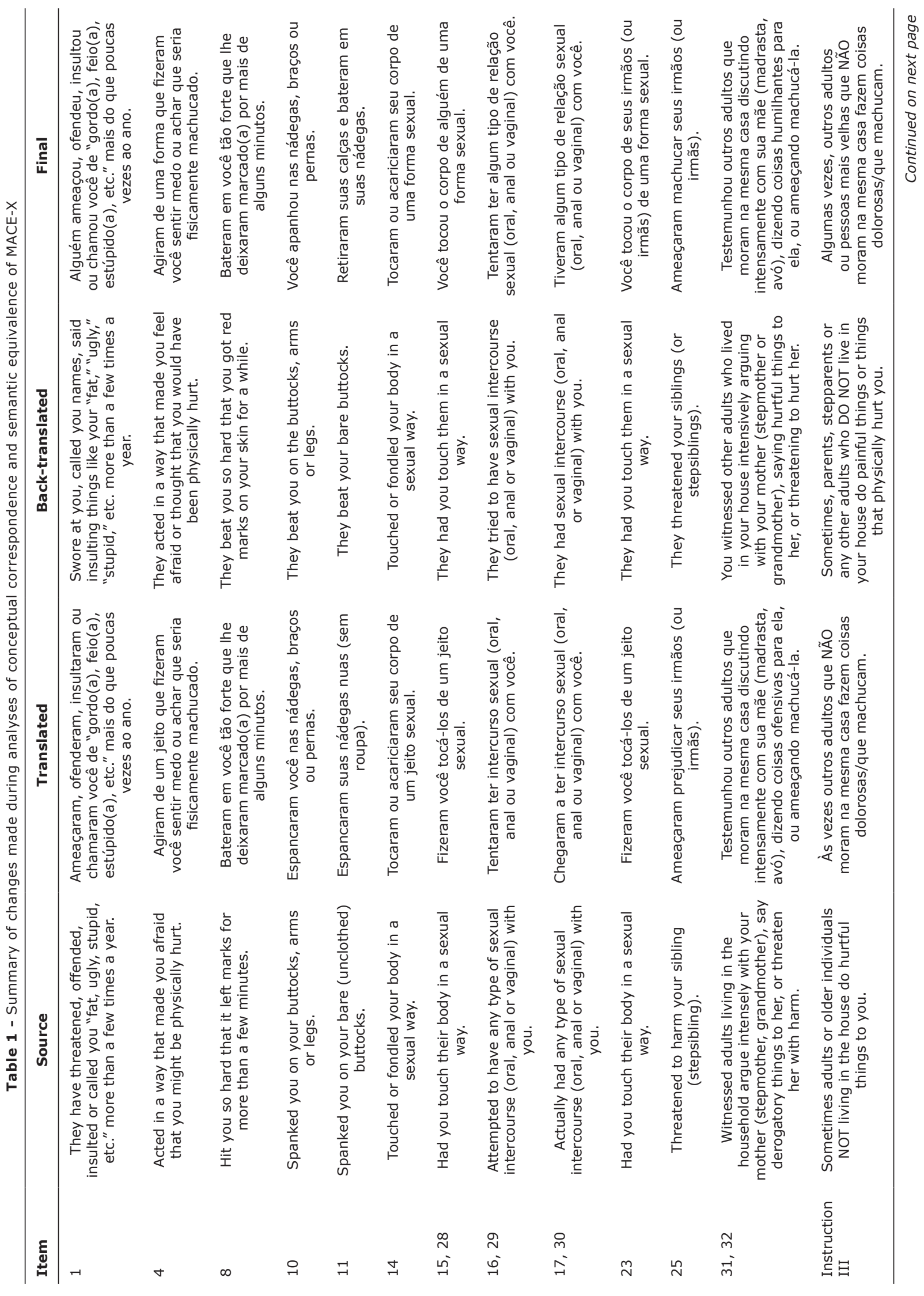



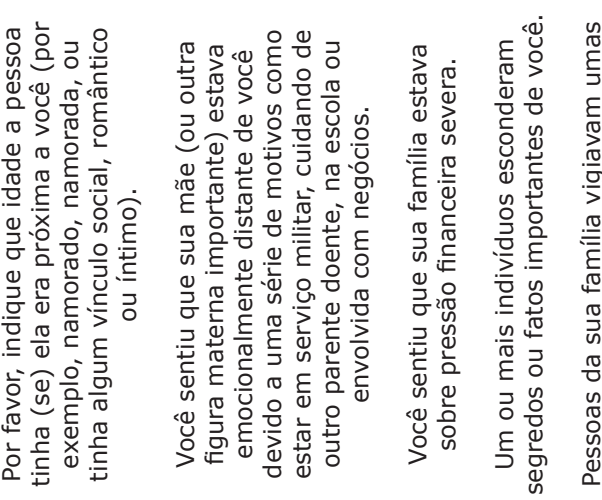

ᄃ

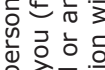

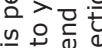

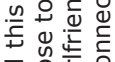

믕 은

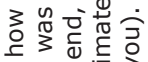

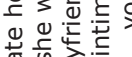

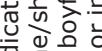

.

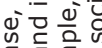

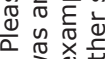

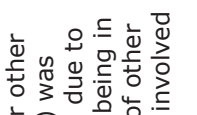

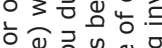

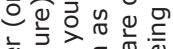

吾它

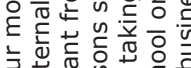

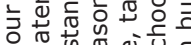

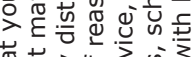

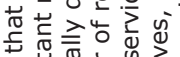

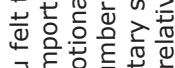

ว ठำ

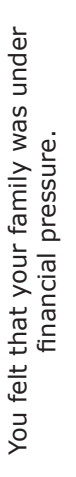

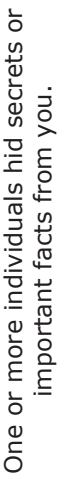

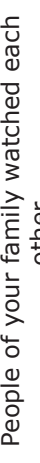

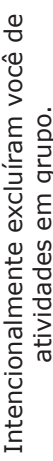

잉 흐의 울

ญ्ष

เ $>\frac{10}{2}$

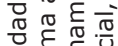

v

궁흐윰을

금 웜

든 융 $\stackrel{0}{ᄃ}$

ㅎํㄴ음음

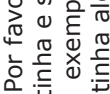

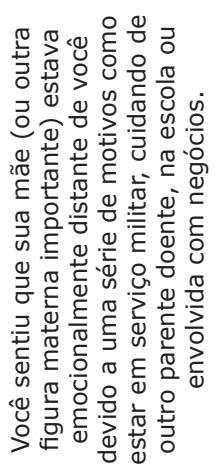

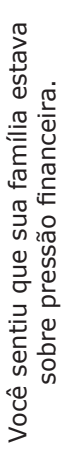

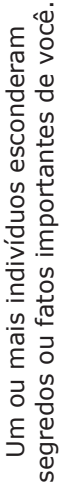

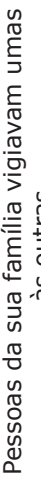
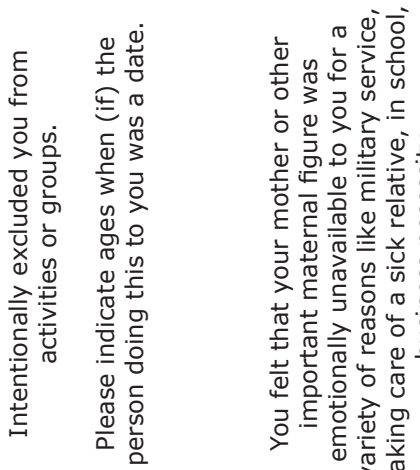

ㅎㅃ은.

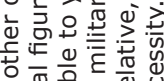

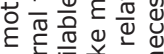

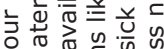

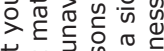

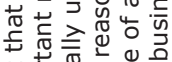

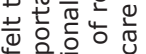

은으

כ

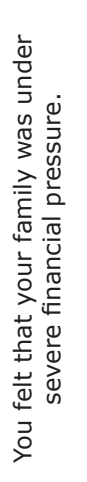

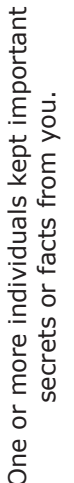

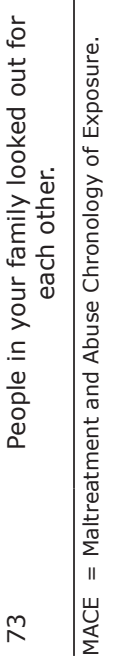

\section{Discussion}

The goal of this study was to translate and crossculturally adapt the content of MACE, MACE-X and MAES to the Brazilian Portuguese language. The end products were three scales for investigation of many forms of childhood maltreatment, including emotional neglect, non-verbal emotional abuse, parental physical maltreatment, parental verbal abuse, peer emotional abuse, peer physical bulling, physical neglect, sexual abuse, witnessing interparental violence and witnessing violence to siblings. Additionally, these instruments allow researchers to identify age at exposure to individual forms of violence, as well as the feelings involved, such as helplessness or terror. The final versions of the instruments are available as online supplementary material of the current study.

This study followed recommended guidelines for cross-cultural adaptation suggested by the International Test Commission, ${ }^{13}$ World Health Organization (WHO), ${ }^{16}$ and well-regarded works such as Beaton et al. ${ }^{14}$ and Guillemin et al. ${ }^{15}$ However, it should be noted that there is no consensus on how to adapt an instrument for another cultural setting and there are some disagreements. For example, with regards to the translation step, we decided to select a high-qualified translator with good knowledge of early life stress terminology, as recommended by the WHO, ${ }^{16}$ rather than a translator with no experience in the field, as suggested by Guillemin et al. ${ }^{15}$ Furthermore, the WHO states that the translator could be someone familiar with English-speaking culture whose native language is the language of the target culture. ${ }^{16}$ On the other hand, there are no disagreements concerning the back-translation step, which was performed by an independent native English speaker fluent in both idioms who has no knowledge of the questionnaire. ${ }^{15,16}$ Regarding the committee review, a multidisciplinary panel was assigned to verify inadequate concepts in the translation and inconsistencies between the source version, translated version and back-translated version. In accordance with the International Test Commission guidelines, ${ }^{13}$ the committee review judged both linguistic and psychological aspects of the instrument with a view to compiling evidence on the equivalence of all language versions.

Furthermore, it should be highlighted that research into childhood maltreatment usually assesses traumatic experiences retrospectively, which could make information less accurate, especially when participants are only asked to identify whether a given event occurred or not. However, in contrast with other instruments, the MACE scale requires the respondent to indicate when the traumatic experience occurred and who was responsible for it. This additional information could prove crucial, 
because it may help the respondent to provide accurate information about traumatic experiences and it helps the investigator to comprehend the effect of chronic stress, providing data on the total duration of childhood maltreatment exposure.

Nevertheless, evidence has mounted documenting that childhood maltreatment increases the risk of psychopathological conditions, such as depressive and anxiety disorders. Such conditions may affect retrieval of traumatic memories that could potentially bias retrospective MACE scores. However, there is no evidence of such an effect on the MACE scale, which is another important improvement related to this instrument's reliability. For example, levels of symptoms of depression and anxiety together only account for approximately $3 \%$ of the variance in MACE retest scores. This suggests that MACE self-report measures of childhood maltreatment exposure are highly consistent over years, regardless of the severity of psychopathological conditions.

Finally, future studies should consider testing the availability and reliability of the three translated Brazilian Portuguese versions of the instrument (MAES, MACE, and MACE-X), as previously conducted in a German study, ${ }^{17}$ which also investigated the psychometric properties of the MACE instruments.

\section{Acknowledgements}

We are very grateful to Dr. Martin $\mathrm{H}$. Teicher for his permission and help.

\section{References}

1. Krug EG, Dahlberg LL, Mercy JA, Zwi A, Lozano R. World report on violence and health. Geneva: World Health Organization; 2002.

2. Teicher MH, Tomoda A, Andersen SL. Neurobiological consequences of early stress and childhood maltreatment: are results from human and animal studies comparable? Ann $\mathrm{N}$ Y Acad Sci. 2006;1071:313-23.
3. Andersen SL, Teicher $\mathrm{MH}$. Desperately driven and no brakes: developmental stress exposure and subsequent risk for substance abuse. Neurosci Biobehav Rev. 2009;33:516-24.

4. Fairbank JA, Fairbank DW. Epidemiology of child traumatic stress. Curr Psychiatry Rep. 2009;11:289-95.

5. Roy CA, Perry JC. Instruments for the assessment of childhood trauma in adults. J Nerv Ment Dis. 2004;192:343-51.

6. Bernstein DP, Fink L, Handelsman L, Foote J, Lovejoy M, Wenzel K, et al. Initial reliability and validity of a new retrospective measure of child abuse and neglect. Am J Psychiatry. 1994;151:1132-6.

7. Bernstein DP, Stein JA, Newcomb MD, Walker E, Pogge D, Ahluvalia $T$, et al. Development and validation of a brief screening version of the Childhood Trauma Questionnaire. Child Abuse Negl. 2003;27:169-90.

8. Bifulco A, Brown GW, Harris TO. Childhood Experience of Care and Abuse (CECA): a retrospective interview measure. J Child Psychol Psychiatry. 1994;35:1419-35

9. Felitti VJ, Anda RF, Nordenberg D, Williamson DF, Spitz AM, Edwards $V$, et al. Relationship of childhood abuse and household dysfunction to many of the leading causes of death in adults. The Adverse Childhood Experiences (ACE) Study. Am J Prev Med. 1998;14:245-58.

10. Bifulco A, Bernazzani O, Moran RM, Jacobs C. The childhood experience of care and abuse questionnaire (CECA.Q): validation in a community series. Br J Clin Psychol. 2005;44:563-81.

11. Grassi-Oliveira R, Cogo-Moreira H, Salum GA, Brietzke E, Viola TW, Manfro GG, et al. Childhood Trauma Questionnaire (CTQ) in Brazilian samples of different age groups: findings from confirmatory factor analysis. PLoS One. 2014;9:e87118.

12. Teicher $\mathrm{MH}$, Parigger A. The 'Maltreatment and Abuse Chronology of Exposure' (MACE) scale for the retrospective assessment of abuse and neglect during development. PLoS One. 2015;10(2):e0117423.

13. International Test Commission (ITC). ITC guidelines for translating and adapting tests [Internet]. 2010 [cited 2014 Apr 04]. https:// www.intestcom.org/files/guideline_test_adaptation.pdf

14. Beaton DE, Bombardier C, Guillemin F, Ferraz MB. Guidelines for the process of cross-cultural adaptation of self-report measures. Spine (Phila Pa 1976). 2000;25:3186-91.

15. Guillemin F, Bombardier C, Beaton D. Cross-cultural adaptation of health-related quality of life measures: literature review and proposed guidelines. J Clin Epidemiol. 1993;46:1417-32.

16. World Health Organization (WHO). Process of translation and adaptation of instruments [Internet]. 2015 [cited 2015]. http:// www.who.int/substance_abuse/research_tools/translation/en/

17. Isele $D$, Teicher MH, Ruf-Leuschner M, Elbert T, Kolassa I-T, Schury $\mathrm{K}$, et al. KERF - Ein Instrument zur umfassenden Ermittlung belastender Kindheitserfahrungen. Erstellung und psychometrische Beurteilung der deutschsprachigen MACE (Maltreatment and Abuse Chronology of Exposure) Scale. Z Klin Psychol Psychother (Gott). 2014;43:121-30.

\section{Correspondence:}

Rodrigo Grassi-Oliveira

Post-Graduate Program in Psychology, PUCRS

Av. Ipiranga, 6681, prédio 11 , sala 936

90619-900 - Porto Alegre, RS - Brazil

E-mail: rodrigo.grassi@pucrs.br 